•科普・

\title{
奇妙缤纷 “铬舞会”
}

戴玮璇\$, 张来英*, 朱亚先 ${ }^{*}$

厦门大学化学化工学院, 福建 厦门 361005

摘要：通过拟人化舞会场景的设置，介绍铬及其化合物的相关性质和应用。

关键词: 铬; 性质; 应用

中图分类号: G64; O6

\section{Chrome's Wonderful Party}

Weixuan Dai ${ }^{\S}$, Laiying Zhang *, Yaxian Zhu *

College of Chemistry and Chemical Engineering, Xiamen University, Xiamen 361005, Fujian Province, P. R. China.

Abstract: Through the setting of anthropomorphic dance scene, the properties and applications of chromium and its compounds are introduced.

Key Words: Chromium; Property; Application

有人轻轻拍了拍他的肩膀。

他转过头, 映入眼帘的是一座堂皇富丽的大厅。

“这里是铬国王与王后举办的舞会现场, 先生。”拍他肩膀的人提醒道, “舞会就要开始了。”

\section{1 序曲}

“铬？”他打量着四周, 这才发现大厅帷幔莫名的熟悉, 有些像老师课上讲过的卢瑟福提出的 原子结构模型。他数了数, 24 个小行星绕着一个中心缓缓运动着。

一位有着银白色眼睛和头发的少女走过来: “我是 24 号元素铬, 住在元素王国第 4 周期、VIB 族。”

她轻轻提起银白色的波浪般的裙摆, 向他行了一个屈膝礼: “请允许我带您参加这一场舞会 吧。”

“1797 年法国化学家沃克兰在西伯利亚红铅矿中发现了我们。”她悠悠地转了一圈, “1798 年, 他给我们命名为铬, 来自希腊语, 意为颜色。”

他有点困惑： “颜色? 可是你们好像只有一种颜色......” 他看向大厅中站着的铬小姐们一一那 实在很好认，她们都穿着美丽的银白色的礼服。

少女回答道: “先生莫急, 等参加完舞会, 您自然就会明白了。”

正说着, 人群鼓起掌来, 原来是铬国王与王后来到了大厅。国王举起银白色的权杖, 在透明的

收稿: 2020-07-10; 录用: 2020-07-23; 网络发表: 2020-08-12

“通讯作者, Email: wuzhly@xmu.edu.cn; yaxian@xmu.edu.cn

${ }^{8} 2017$ 级本科生

基金资助：国家基础科学人才培养基金项目(J1310024)；2017 年厦门大学教学改革研究项目(JG20170222) 
地面上划下一个个巨大而神秘的图案: “我宣布, 舞会开始!”

他蹲下来摸了摸地面，惊讶道：“地面是玻璃, 铬这么容易就能在玻璃上画画吗？”

“那当然了! ” 少女骄傲地说道, “我们可是世界上最硬的金属！你知道莫氏硬度吗？我们有 8.5 哦！因此, 本小姐经常被镀在其他金属的表面作为保护层呢！”

侍从补充道: “铬小姐的用途可广泛啦。由于她机械强度好, 且有抗腐蚀性能, 钢铁合金中常 有她的身影。比如您日常生活中经常用到的不锈钢, 有很好的耐热性、耐磨性和耐腐蚀性, 这其中铬 小姐的贡献可不小哦! 她在不锈钢中的含量可达 $20 \%$ 左右呢 ${ }^{[1]}$ 。还有, 您生活中经常见到的光亮的 物体，比如门把手，就是镀铬层哦…...”

\section{2 色彩缤纷}

四下响起了悠扬的乐曲声, 铬小姐挽着有不同浓度的酸先生、碱先生等众多化学界名流, 随着 乐声的节拍跳起探戈。突然间一个转身, 她们的裙子全都变了颜色！有深遂的灰蓝色、类似潮水的 灰绿色、像天空的蓝绿色, 还有亮绿色、紫色、橙红色、柠檬黄色......像是无数道交织在一起的彩 虹, 缤纷而绚丽, 直叫他眼花缭乱。

他挠挠头, 差郝而不解道: “我一直以为金属的颜色就是银白色, 很单调, 没想到色彩这么丰 富。”

默默跟在他身后的侍从说: “铬是副族元素, $d$ 轨道上的电子未充满, 二价铬、三价铬离子的电 子吸收可见光发生 $d-d$ 跃迁, 呈现蓝色、绿色等不同的颜色; 虽然六价铬没有 $d$ 电子, 但有效核电 荷大，可以发生荷移跃迁，呈现黄色、橙色。”

看着满脸惊奇的他, 少女指着身着五彩裙子的铬离子小姐们, 问道: “猜猜看, 这几位姐姐是几 价铬? ”

“二价？三价？”他猜道。

“我们都是三价铬哦。” 铬小姐们笑开了, “神奇吧！我们和不同离子一起, 会显现出不同的颜 色哦。硫酸铬是红棕色的, 硝酸铬是绿色的, 氯化铬是紫色的 ${ }^{[1]} \ldots . .$. ”

少女看着他听得入神: “还有啊, 三价铬盐和水姐姐是好朋友, 她们和水姐姐一起时色彩缤纷。 比如, 硫酸铬小姐独舞时穿的是棕红色的裙子, 和六个水姐姐一起时呈现出美丽的绿色, 如果拉上 十八个水姐姐就变成漂亮的紫色啦 ${ }^{[2] . . . . . . ” ~}$

“好神奇!”

他的眼睛又被铬小姐们佩戴的饰品深深地吸引了, 祖母绿、翡翠、翠榴石、沙弗莱石、碧胥、 红宝石……光彩夺目。

铬小姐被他看得有点不好意思, 说不出话来。

红宝石说: “我们原本是无色透明的, 美丽的铬姐姐的到来才带给我们这么鲜亮的迷人色彩。”

“这是因为舞伴们的性格、结构不同, 带来的能量差不同, 铬小姐电子跃迁吸收的能量不同, 呈现的互补色就不一样啦。”少女补充道。

“咦, ”他似乎又发现了新大陆, “怎么有几位铬小姐的裙子好像没有变颜色? 和她们跳舞的是 谁?

“那几位是浓硫酸、浓硝酸和王水先生。”侍从轻声说道, “铬小姐和这类强氧化性酸在室温 下不会发生明显的反应, 这种现象叫做铬的针化。”

还没等他回过神来, 大厅中央出现了一位亭亭玉立、穿着红色长裙的三氧化铬小姐, 舞台一侧 走来了穿着白色礼服的氢氧化钠先生, 另一边水姐姐也朝大厅缓步走来。

三人手一拉, 现场沸腾了起来。红色的长裙染上了斑斑点点的橙色和黄色, 渐渐地, 色块越来 越大, 变成黄色, 裙边甚至缭绕着棕黄色缥缙的雾气。

他看得云里雾里, 不得其解。 
侍从小声解说道: “三氧化铬小姐有强氧化性, 是一种酸性氧化物, 和氢氧化钠先生在一起, 只要遇上一点水, 就会发生剧烈的反应, 同时放出很多热量, 使得部分三氧化铬小姐升华成一种棕 黄色的气体 ${ }^{[1-3]}$ 。”

就在这时，身着绿色和棕黑色礼服的二位妹妹从他们身边走过。

“这位是?”

“是三氧化二铬和二氧化铬姐妹。”侍从低声告诉他。

“三氧化二铬又叫铬绿, 常被作为绿色颜料, 具有酸碱两性。二氧化铬是三氧化铬分解为氧化 铬的中间产物, 是铬家族的第三种主要氧化物, 具有金属的电导率。她的铁磁性质使它在磁带和录

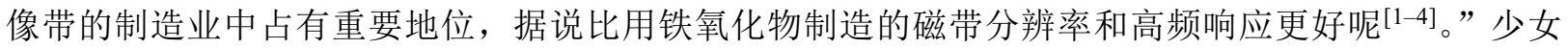
耐心地介绍道。

\section{3 舞会的主角}

一位穿橙红色套裙的小姐姗姗来迟。

“这位是铬家族的掌门大小姐一一重铬酸钾, 大家叫她 “红矾” 姐。”侍从适时地告诉他。

“各位，抱歉，我来迟了，一位酒后驾车的帅哥把我给耽搁了……”红矾姐向大家招了招手。

少女看出了他心中的不解: “红矾姐个性刚强, 她能将乙醇氧化成乙酸, 颜色由橙色变绿色, 改 变十分明显。人类用她的这一特性来判断司机是否酒后驾车。”

“噢, 原来如此。”

“红矾姐旗下的公司做跨国贸易, 产品主要分为两大类：铬酸盐与重铬酸盐, 被广泛应用于基 准物质、颜料等, 油漆、油墨、橡胶与陶瓷也都有她们的身影, 产品遍布世界各地呢!”

“下面由红矾姐给大家表演她的拿手好戏。”主持人说道。

只见红矾姐施施然来到舞台中央, 牵起氢氧化钠先生的手, 伴着节拍轻轻旋转, 她的橙红色的 裙子变成了黄色; 一曲罢, 她交换了一位舞伴, 与酸先生共舞, 翩然舞动中, 飘飞的裙裙又恢复成 了橙红色。

“这是六价铬在不同介质的奇妙存在形式。”少女在纸上写下了方程式:

$$
2 \mathrm{CrO}_{4}^{2-}+2 \mathrm{H}^{+} \rightleftharpoons \mathrm{Cr}_{2} \mathrm{O}_{7}^{2-}+\mathrm{H}_{2} \mathrm{O}
$$

一曲终了, 人群围成一圈, 一位和红钒姐穿着同样橙红色裙子的少女, 将为大家表演一个 “火 山爆发”的小魔术。只见她将喷灯对准自己的裙摆的一角, 开始把它点燃。

“哇！”他惊叫道。

少女微笑着说道: “那是重铬酸铵——红钒姐的妹妹。注意看, 奇迹就要发生了! ”

只见她漂亮的裙子, 从下摆开始燃烧起来, 嘶嘶作响, 暗绿色的固体从燃烧处被气体冲起来, 像火山爆发一样, 源源不断地酒落并覆盖在裙摆上。

他惊奇地拍起了手。

“这表现了重铬酸盐的不稳定性, 六价铬直接氧化铵根离子, 生成绿色的三氧化二铬固体和氮 气。”少女解释着并写下了反应的方程式:

$$
\left(\mathrm{NH}_{4}\right)_{2} \mathrm{Cr}_{2} \mathrm{O}_{7}=\mathrm{Cr}_{2} \mathrm{O}_{3}+\mathrm{N}_{2} \uparrow+4 \mathrm{H}_{2} \mathrm{O}
$$

他挠了挠耳朵: “想起来了, 老师上课时有讲过……”

圆舞曲又响起来, 铬小姐们再次与舞伴跳起舞来, 舞会现场五颜六色, 不断变幻着一一橙红、橙 黄、黄、黄绿、绿、蓝绿、蓝、紫……

\section{4 水中芭蕾}

“我领你去水下舞场看看吧! ”于是, 他们钻进一个透明的泡泡, 游走在水中。

只见双氧水款款而至, 乙醚先生也快步走来, 硫酸先生请来了红矾姐, 四个人手拉手跳起了水 
中芭蕾。乙醚先生体态轻盈, 浮在水上像铺了一层无色透明的水毯, 红矾姐和双氧水钻了进去, 就 像被施了魔法似的，无色透明的进子一下子变成了蓝宝石色。

而他们刚刚经过的水相却变成了灰绿色, 还不停地冒着气泡。他们在气泡的推动下摇曳着, 更 像是一个个舞动的小天鹅。

他被深深地吸引了。

少女道: “重铬酸钾和过氧化氢在酸性环境中发生过氧链转移, 生成了宝蓝色的过氧化铬。过 氧化铬虽然美丽, 但是性格暴躁, 只有乙醚、戊醇先生等有机溶剂可以使她安静下来。”

“可是, 为什么水中是灰绿色的呢? 气泡又是什么呢? ”

“过氧化铬不喜欢水先生, 在水中就会大发脾气, 把双氧水的电子抢过来, 生成三价铬离子与 氧气。”

“可是, 美丽的红钒姐不见了。”他遗憾地说。

这时, 氢氧化钠先生走过来, “莫急, 莫急!” 他转身跃入水中, 拉起了三价铬离子与双氧水, 说变就变, 灰绿色的溶液转变为黄色。

“你看, 双氧水也不示弱, 在氢氧化钠先生帮助下, 又把电子夺回来了, 铬又回到六价喽。现 在考考你, 下一步如何把红钒姐重新请出来？”

他脑子里浮现出刚才红钒姐的表演, “看我的!” 他一边说着一边游过去, 把氢氧化钠先生推上 岸, 然后跃起来把酸先生拉下水, 于是, 红钒姐笑盈盈地又回来了。

“我能试着和红矾姐一起跳舞吗? ”

“恐怕不行。”少女道。

载着他们的气泡慢悠悠地上升，带他们走出了水下会场。

\section{5 亦正亦邪}

走出水下会场, 他们拐入一条长长的走廊。走廊两边的墙壁上, 是截然不同、格格不入的两幅 画面。左边是人类从出生到成长, 神采奕奕, 飞禽走兽自由自在, 生机勃勃; 而右边, 则是成吨的 废水、废渣倾倒, 污染了水源, 大批牛羊死亡, 人们居住的村庄也变成了“癌症村”, 触目惊心。

“这是……? ”他问道。

少女指了指左边的画，脸上露出了笑容：“三价铬也是铬最稳定的氧化态，不易被胃肠道吸收， 在皮肤表层与蛋白质结合为稳定络合物, 毒性不大。而且, 三价铬与人类的健康密切相关, 还是人 体所必需的微量元素呢, 参与脂类和糖代谢, 是葡萄糖耐量因子的组成部分, 能够增强胰岛素的作 用; 又能影响机体的脂质代谢, 降低血中胆固醇和甘油三酯的含量 ${ }^{[4,5] 。 ” ~}$

转过身，少女的脸阴沉了下来: “六价铬化合物就普遍具有较高的毒性，毒性高于三价铬百倍， 对环境有持久危险性。六价铬在红细胞内被还原为三价铬, 使谷胱甘肽还原酶活性受到抑制, 血红 蛋白变性影响氧运输, 超标可破坏人体的血液; 接触会导致多种细胞损伤、皮肤过敏; 更可能造成 遗传性基因缺陷；吸入可能致癌；而且六价铬又易被吸收并在体内蓄积 ${ }^{[4,5]}$ 。”

少女意味深长地说道: “这就是铬的两面性, 是一把锋利的双刃剑。所以, 刚才我不让您与她们 跳舞。”

“人类为什么制造那么多含铬的废水和废渣呢? ”

“那是因为铬的用途广泛啊。”少女得意地继续说。

“铬的光泽度好, 抗腐蚀性强, 硬度大, 熔、沸点都非常高, 极耐磨损, 广泛用作电镀保护涂 层。它的化合物也应用在我们生活的方方面面: 氧化铬是铬绿, 铬酸铅叫铬黄, 作为颜料人们已经 使用了很多年; 铬氧化物的铁磁性质使它在记录磁带制造业占有重要地位; 重铬酸钾和重铬酸钠既 用来制备铬酐、其他铬盐和铬黄颜料, 也用于制造安全火柴、烟火、炸药、油脂漂白剂等; 而铬钾 矾则广泛用于皮革鞣制和染色。” 
侍从看着展现铬污染的那一面墙壁, 喃喃道: “早年间啊, 铬污染事件时有发生。污染源主要来 自生产加工含铬化合物时排放的铬渣, 金属电镀、皮革鞣制、印染等生产也会排放出大量含六价铬 的废物。若不好好处理, 就会发生这样惨痛的事件, 无数生命都会受到不可逆的伤害啊。”

“好在近些年来, 六价铬的污染治理已经有很多方法, 如化学法, 包括化学沉淀法一一通过氧 化还原、离子置换、络合反应等反应使水体中的铬产生沉淀而去除; 氧化还原法一一通过投加还原 性试剂将六价铬还原成三价铬, 再控制 $\mathrm{pH}$ 沉淀, 加热制备出铬绿; 铁氧体法一一使铬离子形成铁氧 体沉淀析出等; 又或者是利用离子交换法, 根据废料中铬的存在形式, 利用相应的阴阳离子交换剂 对铬进行离子交换 ${ }^{[5]}$ 。这样既处理了铬污染, 又得到了有用的物质, 变废为宝, 使铬更好地在生活中 发挥它的长处, 展现它的光芒。”

少女接过话头: “是呀, 铬小姐正和人类友好合作, 富铬酵母(铬酵母)的开发利用就是一个很好 的例子。铬酵母可以指导糖尿病患者合理摄取铬微量元素, 是目前最安全、最有效的方法。”

说着说着, 他们又转回到了舞会大厅。

三价铬小姐和三个吡啶甲酸正在一起舞蹈, 形成了玫瑰红色结晶状的吡啶甲酸铬。

“吡啶甲酸铬是稳定的络合物, 是脂溶性的, 可顺利通过细胞膜直接作用于组织细胞, 是动物 的好朋友, 很容易被动物吸收哦。她可调节血糖, 增强胰岛素活性, 改善人体糖代谢, 从而预防和 改善糖尿病乏力、多尿、口渴等症状, 可防止糖尿病合并症的产生呢 ${ }^{[6] 。 ”}$

少女真是位博学多才的神奇女神。

舞会结束了, 各种神奇变幻吸引着他的眼睛, 但其中隐含的知识更是牵动了他的心.......

\section{参 考 文 献}

[1] 宋天佑. 无机化学教程. 北京: 高等教育出版社, 2012.

[2] 刘新锦, 朱亚先, 高飞. 无机元素化学. 北京: 科学出版社, 2010 .

[3] 王大全. 精细化工辞典. 北京: 化学工业出版社, 1998.

[4] 宋天佑, 徐家宁, 程功榛. 无机化学(下册). 北京: 高等教育出版社, 2004.

[5] 李爱琴, 唐宏建, 王阳峰. 中国环境管理干部学院学报, 2006, 16 (1), 74.

[6] 乔煦玮, 吴玥霖, 曾凡骏. 食品工业, 2011, 32 (1), 85. 